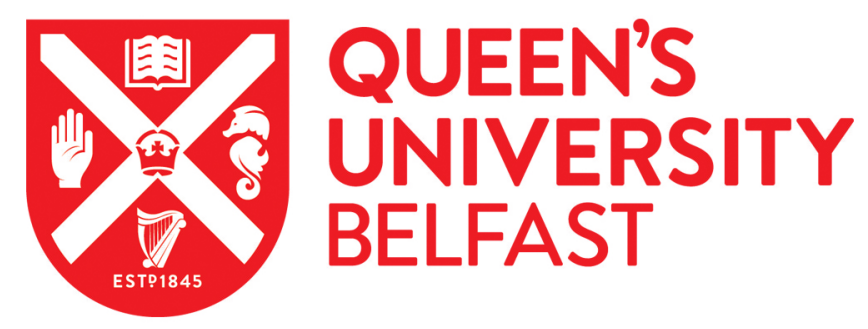

\title{
Emotional displays: Nurse educators engaging and reflecting on their own emotional displays in preparing nursing students for the emotional complexities of nursing practice.
}

Leonard, L. (2017). Emotional displays: Nurse educators engaging and reflecting on their own emotional displays in preparing nursing students for the emotional complexities of nursing practice. Nurse Education in Practice, 26, 21-26. https://doi.org/10.1016/j.nepr.2017.06.001

Published in:

Nurse Education in Practice

Document Version:

Peer reviewed version

Queen's University Belfast - Research Portal:

Link to publication record in Queen's University Belfast Research Portal

Publisher rights

(c) 2017 Elsevier Ltd. This manuscript version is made available under the CC-BY-NC-ND 4.0 license http://creativecommons.org/licenses/bync-nd/4.0/ which permits distribution and reproduction for non-commercial purposes, provided the author and source are cited.

\section{General rights}

Copyright for the publications made accessible via the Queen's University Belfast Research Portal is retained by the author(s) and / or other copyright owners and it is a condition of accessing these publications that users recognise and abide by the legal requirements associated with these rights.

Take down policy

The Research Portal is Queen's institutional repository that provides access to Queen's research output. Every effort has been made to ensure that content in the Research Portal does not infringe any person's rights, or applicable UK laws. If you discover content in the Research Portal that you believe breaches copyright or violates any law, please contact openaccess@qub.ac.uk. 


\section{Introduction}

The complexity of modern healthcare draws attention to what skills, knowledge and attributes are required of professional nurses and of nurse educators in preparing nursing students to provide care. Traditional models of nurse education emphasised the importance of clinical skills acquisition, but the move of nurse education in many countries to the Higher Education (HE) sector is seen also as developing theoretical knowledge, such as critical thinking and decision-making (Mundy and Denham,2008; Shields and Reid-Patton, 2011). Many debates have been and continue to be outlined in a range of literature in regard to how best to develop both theoretical knowledge and clinical skills in nursing students (Corlett, 2000; Distler, 2007; Carter, 2009; Price et al. 2011; Darbyshire and McKenna, 2013). However while technical and theoretical nursing knowledge are important, nursing practice and nurse education cannot be limited to these (Sargent, 2012; AdelmanMullally et al.2013). Nursing practice and nurse education involve interpersonal relationships and a greater understanding needs to be given to the emotions that arise in such relationships. In this paper I examine expressions of emotions and their relationship to and appropriateness in nursing practice and education. In particular I examine whether selfunderstanding by attendance to emotions can enhance the role of nurses educators in preparing nursing students for the complexities of modern nursing practice. The paper argues that by engaging and reflecting on emotional aspects of their own work that nurse educators perhaps can begin to better prepare students for the emotional complexities of nursing practice.

Higgs, Burns and Jones (2001) highlight that in professional healthcare practice; three types of knowledge are required: professional craft knowledge, propositional knowledge 
(theoretical knowledge) and personal knowledge of self and in relationship to others. This latter knowledge of self in relationship to others is an important aspect of the nurse/patient relationship, but also forms an important part of the relationship between nursing students and those who are often looked to as role models, such as nurse educators, teachers, practice educators and mentors. Nursing practice involves interactive relationships with patients and such relationships bring about a range of emotions. Similarly the relationship between the nursing students and those responsible for their education involve emotional aspects. O' Connor (2008) suggests a need for a better understanding as to how such emotional aspects of a professional role guide professional practice. Sargent (2012) acknowledging the importance of the professional craft and technical aspects of nursing, suggests that there has been an over representation of these, with the emotional and relationship elements of nursing being seen as secondary. O Connor (2008) contends that knowledge of self is often side-lined in traditional notions of professional knowledge and practice.

Horton-Duetsch and Sherwood (2008) hold a similar view, arguing that competent nursing practice is underpinned by self-awareness, including awareness of one's emotions and feelings. Pross, Boykin, Hilton and Gabuat (2010) and Brown (2011) contend that nursing care involves the intentional extension of the self to another and that before extending the self to others in such relationships there is a need to know the self. The knowledge of self includes knowledge of one's emotions and emotional reactions. However within nursing practice and education there is limited focus in developing nurses' knowledge of their emotions or how best to react to emotional issues arising in everyday practice. Failure to understand and address the emotional reactions and experiences which arise in 
relationships within the clinical setting and to recognise the emotional components of nursing practice and education may have detrimental implications for nursing practice and for nurses themselves. Burston and Stichler (2010) highlight how prolonged over extension of the self may lead to emotional exhaustion and burnout and ultimately impacting on the nurse and nursing care. Littlejohn (2012) highlights examples in nursing practice whereby the qualities expressed may be aggressive or hostile, suggesting that these may arise out of fatigue, burnout and failure to deal effectively with emotions.

Smith and Allan (2010) take the view that there is a culture within nursing which does not recognise or acknowledge the need for organisational support in the management of emotions as important features of learning and nursing practice. Freshwater and Stickley (2004) suggest that there is a need to understand the role of emotions in the education and practice of nursing. Greater analysis of emotions may provide deeper understanding of the human interactions and relationship aspects of nursing practice including the relationship aspects in the preparation of student nurses.

\section{Emotions in healthcare practice}

Modern healthcare environments can be emotionally challenging for both patients and staff (Firth-Cozens and Cornwell, 2009). Illness, disability, death and dying often raise a range of emotions for patients and their relatives and can impact either consciously or unconsciously on the emotions of healthcare staff. Allen, Ploeg and Kaasalainen (2012) contend that nurses must work effectively with such emotions; therefore it is important that nurse educators can enable and equip nursing students to gain an understanding of such emotions and to manage them in a manner which is not detrimental to either themselves or their 
patients. Wallbank and Proctor (2013) argue that the ability to engage with emotional aspects of nursing work underpins the provision of good care.

Despite such recognition that nursing is emotionally charged, there has been limited focus into the role of emotions in the formation and preparation of nursing professionals for the emotional aspects of nursing work (Freshwater and Stickley, 2004; Horton-Deutsch and Sherwood, 2008; Landa and Lopez-Zafra, 2010). Current models of nurse education have a focus on technical and theoretical aspects of knowledge and often emphasise the assessment of students' competences and critical thinking, but these struggle to capture the relational aspects of nursing care. While professional standards of conduct and behaviour are set out in normative codes and standards, these give little indication or guidance on how nurses should manage or deal with emotions in the relational aspects of nursing practice. There may be assumptions that nurses have an awareness of the emotions that arise in themselves and their patients and have the necessary skills to deal with such emotions in a way that is beneficial to themselves and those that they care for. Anderson (2002) found that many nurses expressed disappointment that the emotional aspects of nursing work were not addressed in nurse education.

Curtis (2013) makes an important claim, that in nurse education there is lack clarity of where the boundaries of emotional engagement should be and there is often a suppression of perceived negative emotions. This view resonates with a claim by Anderson (2001) that there is often a dissonance between engagement and attachment from and with emotional aspects of caring. These arguments raise questions as to the nature and extent that nurses and nurse educators should engage with the emotional aspects of their work. While emotions and their expression are complex and wide ranging it would appear that there are 
some unwritten emotional display rules within nursing and nurse education. It is not an uncommon expectation that nurses should put on a 'brave face' or to present themselves in a stoical manner unaffected by joy, grief, pleasure, sadness or pain. Schutz and DeCuir (2002) suggest that this may be due to social, cultural and historical influences which have impacted on the public and private expression of emotions in professional practice. Historically professional nursing practice has been shaped and influenced by a largely male medical ideology (Dickson,1993).McQueen (2004) suggests that this influence has meant that traditionally nurses have been expected to be objective in their relationships with patients and to maintain a professional barrier by concealing their emotions. George (2000) and Schutz and DeCuir (2002) suggest that emotions have been thought of as in conflict with rationality. These latter discourses suggest that there is a dominance of objectivity over subjectivity in professional practice. Sutton and Wheatley (2004), Freshwater and Stickley (2004) and Mann (2010) see this as arising from a dominant scientific paradigm which emphasises objective, context free scientific knowledge over other forms of knowledge. This type of objective knowledge has had a strong influence on the practice of bio-medicine which in turn has had a dominating impact on the practice of nurses and nurse education (Mooney and Nolan, 2006). Coulehan and Williams (2003) highlighting some practices within hospital cultures suggest that some traditional models adopt a purely technical view of practice where the professional takes on an objective identity which confines their responsibility to the technical arena with a detachment from patients. Others such as Littlejohn (2003) argue that there is a traditional expectation that nurses and other healthcare providers leave their emotions outside of the working environment. One argument forwarded for such practice by Brunero, Lamont and Coates (2010) is that there is 
a risk that healthcare professionals who lose their objectivity may become overwhelmed by the emotions of the patients in their care. These claims resonate with my own experience as a nurse and nurse educator where often nursing practice was seen by some as undertaking a range of technical and clinical tasks with the patient being seen as the objective recipient of such tasks and the nurse a detached care provider.

\section{Detachment from emotions in nursing}

I have a strong recollection of being reprimanded as a young student nurse by an angry ward sister when I was found quietly crying in the sluice room following the death of a patient for whom I had been caring. I was told that "you will never make a nurse if you do not learn to control such feelings". Since then both in my practice as a nurse and as a nurse educator I have observed and experienced similar attitudes among nurses and nurse teachers which appear to conform to the stance of the ward sister in regard to the expression of emotions; that is, one of detachment from or non-expression of feelings. Zembylas (2007) views this as emotional management that is an attempt to control what we feel based on learned convictions or rules. Such experiences are echoed in a study by Henderson (2001) which reported that some nurses take a detached stance in relation to the emotional aspects of care and focused only on the technical aspects of their work, operating often from a model of nursing as the competent provider of the technical and professional skills aspects of caring. Smith and Allen (2010) claim that such distancing of themselves by nurses from patients is a defence against anxiety arising from engagement with patients' emotions. This is echoed in an earlier study by Morrison (1989) who found that some nurses withdrew emotionally from patients for self-protection. Williams, Dean and Williams (2009) referring to this as emotional hardiness, stress that it is used as a means 
of coping with stressful emotions and experiences. Such detachment, however, contrasts with the view forwarded by Brunero, Lamont and Coates (2010) that emotional engagement is a requirement for excellence in the professional nursing role. Such a view is echoed by Enlers (2008) who argues that there are two dimensions to caring; the competent provision of technical skills and the ability to offer sympathy and emotional support. The development of both theoretical and clinical skills of nursing students are important, but an overemphasis on them may be to the detriment of other aspects of the patient/nurse relationship.

Detachment from emotions or failure in emotional responses to those in their care can lead to accusations of nurses being cold, uncaring and devoid of feelings (Weeks 2012). Landa and Lopez-Zafra (2010) view such practice as a depersonalization, which includes negative responses distancing and negative response by individuals to others.

These concerns have been raised in reports in the United Kingdom( UK) and other countries into abuse and neglect of patients, such as in the UK report into care at Mid-Staffordshire National Health Services(NHS) hospital (Francis 2013)and others such as the Keogh Report (2013); the Care Quality Commission report (2012), the NHS Futures Forum (2012). Other media reports have highlighted incidences of emotional and angry outbursts from nurses or conversely displays of indifference to the needs of patients. These latter are seen by Darbyshire and McKenna (2013, p 305) as "nurses who couldn't care less". Such expressions of indifference or anger are at odds with popular notions of nurses as caring professionals with feelings of empathy towards patients. This notion suggests that nursing practice requires openness towards the feeling of others and to one's self and one's own emotions. This is a view shared by McQueen (2004) who argues that modern nursing practice requires nurses to engage with patients' experiences and emotionally respond to their suffering. 
Despite such expectations, there is limited evidence that nurses are prepared for such emotional aspects of their role.

Nursing practice and nurse education involve interpersonal relationships with patients and students and a greater understanding needs to be given to emotions that arise in such relationships. Gardner (1993) viewed such understanding as an emotional competence encompassing both interpersonal and intrapersonal relationships. The former involves an ability to understand others and to work with them, whereas the latter involves gaining selfawareness and recognition of one's own feelings and to take account of these in social situations. Cadman and Brewer (2001) also suggest that it should be an important element to enhance the skills of 'self-insight' which they see as a vital element in the effective application of emotions. Hurley (2008) also argues that within interpersonal relationships there is a need to be able to communicate in a warm and empathetic manner but also to have self-awareness. For Brunero and colleagues (2010) such empathy and self-awareness include an understanding of one's own feelings and the feelings of others and how to communicate such feelings. Henderson (2001) suggests, however that there continues to be a divergence of views regarding detachment (objectivity) versus engagement (subjectivity) in nursing practice.

This dissonance raises important implications for nurse educators as to how best to develop appropriate emotional responses in nursing practice and what frameworks may best guide emotional engagement. Given the complexity of emotions that arise in diverse contexts in nursing practice and education it may not possible or practical to pre-determine either acceptable of unacceptable reactions to such emotions. Indeed Williams and Stickley (2010) caution against a reductionist approach. Henderson (2001) suggests that different levels of 
emotional engagement will be impeded or encouraged by the different context and circumstances of a particular patient/nurse encounter. This suggests a need for different levels of emotional understanding and management in varying clinical and patient contexts. For example, knowing when a smile would be inappropriate or when expressing signs of sadness or empathy are needed. George (2000) describes such as the ability to perceive emotions, the ability to assimilate and integrate emotions, to have knowledge about emotions and the ability to manage them. Higgs, Burns and Jones (2001) argue that this involves personal knowledge of self and in relationship to others, echoing the claim by Denzin (1984) that self-understanding may be obtained by attending to our emotions. Smith and Allan (2010) argue that paying attention to emotions is a useful way to explore the emotional effects on individuals delivering and receiving care. Such arguments raise questions as to what emotions are appropriate in nursing practice and how nurse educators may help student nurses recognise and deal with emotions in a way that is beneficial to patients and to the nurses themselves.

In nurse education there is often a focus on and expectations of nurse teachers having both theoretical subject knowledge and clinical practice skills (Freshwater and Stickley, 2004; Little and Milliken, 2007). However as Hargreaves (1998) contends subject knowledge, having the correct teaching techniques or competences are necessary but not sufficient conditions for being a good teacher. As Corcoran and Tormey (2013) argue that the ability to work with emotion is also an important teaching skill.

For Jennings and Greenberg (2008), how teachers relate, teach and model, emotional constructs are important in the development of students. Just as nursing practice involves an emotional dimension; emotions are an integral part of any educational activity 
and are involved in every aspect of the teaching and learning process (Schutz and Lanehart, 2002 and Goetz et al, 2013). Zembylas (2006) sees emotional knowledge as an important part of teaching. Claxton (2008)argues that one of the most powerful influence on students' learning that teachers make are the qualities that they present in themselves when they are teaching Hargreaves (1998) views such qualities as including intuition and a disposition to caring. In the context of nurse education such views are echoed by Adelman-Mullally and colleagues (2013) who suggest that an essential element of caring for patients can be communicated to students or not by role modelling by nurse teachers. Drumm and Chase (2010); Newton (2010); Straughair (2012);Bray, O Brien, Kirton, Zubairu and Christiansen (2013) suggest that in order for students to provide compassionate care, nurse educators need to model caring attitudes themselves by demonstrating their own compassionate behaviours. O' Connor (2006) echoes this view by emphasising the importance of care and commitment of the teacher to the student. Allen, Ploeg and Kaasalainen (2012) and Hargreaves (2001) suggest that this requires teachers to have a genuine emotional understanding and empathy towards others. Similar arguments are made by Shields and Reid-Patton (2009) who contend that the expression of kindness to others is a cornerstone for practice as a teacher. Newton (2010) also argues that nurse teachers play an important role in the teaching of compassion by role modelling the values underpinning compassion. As Williams and Stickley (2010) argue, patient care can be shaped by the positive influence of nurse educators on the attitudes and behaviours in student nurses.

Carter (2009) and Titsworth, et al (2010) also argue in stressing the importance of teacherstudent relationships, argue that students' emotions and feelings towards others are developed positively or negatively as a result of behaviours exhibited by the teacher. Similar 
views are expressed by Sutton and Wheatley (2003) who suggest that teachers' emotions may influence, motivation and behaviour. Duchscher (2000) suggests that nurse teachers can by way of their teaching methods and relationships with students, subtly socialize the behaviour of students. She argues that values can be projected by educators which shape the students learning and their perceptions of the professional nursing practice. Other such as Vanlaere and Gastmans (2007) claim that role models are important in developing nurses' disposition to care.

Such arguments suggest that how nurse teachers as role models, display their interpersonal behaviours and expression of emotions in their relationships with students may be a significant part in forming empathetic practice in students. It is important thus that nurse teachers themselves have knowledge of their own emotions and how they express such emotions in their practice. Feather (2009) views this emotional knowledge as an important aspect of role modelling and leadership in nursing. Despite these arguments, there is a lack of clarity as to how nurses and nurse teachers may best manage emotions in their daily practice and questions arise as to what emotions nurse teacher should display and model to students.

\section{Social and cultural influences}

Van Veen and Lasky (2005) suggest that social and cultural influence teacher's expression of some emotions while prohibiting the expression of others. Similar views are shared by Sutton (2004) who argues that teachers often regulate their emotions because of display rules associated with the moral and cultural aspects of emotions. Such "cultural display rules" are often seen as requiring suppression of emotions (Cooper and Olsen, 1996). 
Hasting (2007) refers to this as an expectation that teachers manage their emotions by masking feelings.

Beard and Malkki (2005,) argue that there has been a privileging of the rational over the affective in teaching and learning and that emotions are seen as problematic, and that emotions in learning and teaching receive little or no attention. Such arguments resonate with my own experiences within nursing and nursing education, where I have often observed a stoical approach to emotions.

Carter (2009) suggests the teacher-student relationship is the most fundamental component of teaching and that such interpersonal relationships, shape and affect the development of student nurses' professional practice. Smith and Allen (2010) however suggest the teacher student relationship may be affected by conflicts and emotions that may be unconsciously or consciously suppressed. Sutton (2004) refers to this as emotional regulation and found that some teachers were reluctant to express perceived negative emotions such as anger. George (2000) cautions that, such lack of expression of feeling inhibits decision-making and can be the cause of human dysfunction. Hastings 2004; Van Veen and Lasky, 2012; and Farouk, 2012) highlight how emotions such as guilt, anxiety and disappointment can significantly impact on the working lives of teachers Jennings and Greenberg (2009) caution that failure to deal effectively with this can lead to emotional exhaustion where the teacher becomes cynical and uncaring. In the context of nurse teachers as role models, there is a risk that students may model such behaviours when dealing with patients. As Brown (2011) suggests, expressions of incivility in classrooms may transcend to clinical practice. Conversely, suppression of emotions by teachers may reinforce within students that the social-cultural masking of feelings is an appropriate way 
to deal with workplace emotions, thus giving credence to accusations of nurse as being cold and uncaring. A contrary view may be that non-suppression could lead to inappropriate outbursts among nurses. There is a need therefore to examine ways in which nurse teachers can be enabled to manage emotions in a way which is positive for themselves and for students.

\section{Reflection and self-awareness}

Caruso, Mayer and Salovey (2002) and Schutz and Decuir (2002) suggest that abilities to attend to one's emotions and the emotions of others has a dimension which requires selfreflection. Brunero, Lamont and Coates (2010) also suggest that there is a need to manage one's own emotional responses in nursing education through self-awareness. Vanalaere and Gastmans (2007) contend that one way of developing caring in nursing may be through critical companionship in which student nurses are encouraged by those who are responsible for their education, to reflect on their practice. Driscoll and Teh (2001) see reflection as helping practitioners to make more sense of difficult and complex practice. Notions of reflection arise from early work by Dewy (1933) who saw reflection as an act that involves the whole person including his or her emotions (Ruth-Saad 2003) and today reflective practice has become part of the discourses in nursing education. Matsuo (2012) argues that reflection encourages individuals to be receptive to alternative ways of reasoning and behaving and to encourage nurses to think about their interactions with patients. Brown (2011) sees reflection as allowing the professional to explore values and behaviours which may not be congruent with caring roles and to explore alternate ways of dealing with the emotional and other aspects of the professional role.) Grealish and Smale (2011) also suggest that nurse teachers can help students reflect on their practice by 
critically examining feelings, experiences, interactions and practice. Aragao (2011) argues that through reflection individuals are able to identify emotional challenges and to deal with them more effectively. Such views are echoed by Vanlaere and Gastmans (2007) who suggest that self-consciousness (reflection) and continual self-critique should form part of professional practice. However Walker and Mann (2016) suggest that although there has been encouragement of reflection in nursing this has largely been in relation to the care provided with a lack of development of nurses' reflection on their own emotions. The authors suggest that one way of doing so may through mindfulness training. Sanko et al (2016) refer to mindfulness as paying attention to the moment in an intentional nonjudgmental way. Barret (2017) also argues that self-awareness and self-compassion may be developed through mindfulness training with a view to improving well-being and resilience to provide compassionate care.

While there are many such arguments for the development of reflection and mindfulness as a means of helping students deal with the emotional aspects of their role, the role of reflection and mindfulness training for nurse educators needs also to be explored. RuthSaad (2003) contends that nurse educators have responsibilities in fostering the reflective process in students, but that before doing so they need to believe in the value of reflective practice and set times aside for their own reflections on their practice as role models for students and colleagues. Vanalaere and Gastmans (2007) contend that teachers have to have expertise in reflecting on their own practice. Bain, Ballantyre, Mills and Lester (2002)and Tigelaar, Dolmans, De Grave, Wolfahgen and van der Vleuten (2006) also emphasise the importance of reflection by teachers as part of their professional development. Carter (2009) however, suggests that while reflection is a critical component 
of teaching it is one that is the most undervalued. Kemp and Baker (2013) suggest that there is evidence that the lack of reflection may account for inconsistencies between teacher knowledge and teaching practice.

Lofstrom and Nevgi (2014) suggest that reflecting on their emotions may help teachers to understand their reactions to different teaching situations and to cope with feelings that are difficult or problematic, thus avoiding contagion of negative feelings. Corry and Timmins (2009) however suggest that the teacher must be able to challenge their own assumptions by reflecting on their own teaching. Magno (2010) argues that through reflection, individuals gain an awareness of their strengths and limitations. Others such as Sandars (2009) contend that the process of reflection facilitates understanding of the self and that this in turn facilitates expertise in teaching. This view is echoed by Hagevik, Aydeniz and Rowell (2012) who suggest that such reflection on self and one's practice is an essential component of improving teaching practice. Kuit and Reay (2001) add that by being reflective teachers, this encourages reflection and critical evaluation in students. Titus and Gremeler (2002) contend that it is not uncommon for educators to develop a teaching style without much conscious reflection and this may impact upon students learning. However as Hurley (2008) suggests nurse teachers themselves lack the skills necessary to reflect on emotions. Freshwater and Stickley (2004) recommend that making emotions explicit in the nursing curriculum should be an essential element of developing student nurses into the caring role, but if this is to be developed nurse educators themselves must have a knowledge of self and ones emotions and how they are portrayed to students.

\section{Conclusion}


The feasibility of training in reflection and mindfulness in regard to emotions as part of the on-going practice and development of student nurses and nurse teachers requires further exploration and research. If engagement with the emotional aspects that arise in nursing practice and education are deemed to be an important part of the professional skill set, then it should not be left to individual student nurses to have to navigate such emotional experience without some guidance and assistance. That is not to suggest that there should be some handbook to guide how to deal with the myriad of emotional experiences arising in the professional nursing role, but those with responsibility for the development of nurses need to consider how they themselves can model their own emotions in a positive and caring manner. While some individual nurse teachers may consciously or unconsciously reflect on their practice, there is no evidence of reflection being expected within the regular remit of the practice role of nurse teachers. There may be assumptions that nurse teachers themselves have awareness and ability to reflect of their own emotions and practice and are able to relate to the emotions of others. Consideration might be given by employers and regulatory bodies to including reflection on practice and as a requirement of ongoing professional development. To do so however will require a commitment by employers to giving designated time and training in reflection or mindfulness, specifically around the emotional aspects of the professional role. 


\section{References}

Adelman-Mullaly, T,. Mulder C.K,. McCarter-Spalding, D,. Hagler, D., Gaberson, K,. Hanner, M,. Oermann, M, Speakman, E,. Yoder-Wise, P and Young, P .2013. The clinical nurse educator as leader, Nurse Education in Practice 1(13):29-34.

Allen, D, J. Ploeg, and Kaasalainen, S. 2012. The relationship between emotional intelligence and clinical effectiveness in nursing faculty, Journal of Professional Nursing. 28(4):231-40 Anderson, B. A., Provis, C and Chapel, S.J. (2001) "When it is just too hard to smile!" Australian Journal of hospitality Management, Vol 8(2): 69-72

Anderson, C. (2002). "Workplace violence: Are some nurses more vulnerable?" Issues in Mental Health Nursing, 23, 351-366

Aragao, R. 2011 Beliefs and emotions in foreign language learning. System 39:302-13 Bain, J., Ballantyre, R,. Mills, C and Lester, N. 2002. Reflecting on Practice: student teachers perspectives, Flaxton, Post Presses,

Barret, C. 2017.explring how mindfulness and self-compassion can enhance compassionate care, Nursing Standard 30(21):55-62

Beard, C and Maikki, K. 2005. Student transformation and the interaction between the epistemological and ontological tracks: the wider project of higher education? In Interaction in Educational Domains, 25-36, eds K Tirri and E. Kuusisto Sense Publishers. Bengtsson, J. 2003. Possibilities and limits of self-reflection in the teaching profession. Studies in Philosophy and Education 22:295-316 Bray L., O Brien, M., Kirton, J,. Zubairu, K and Christiansen, A .2014. The role of professional education in developing compassionate practitioners: A mixed methods study exploring the 
perceptions of health professional and pre-registration students. Nurse Education Today $34(3): 480-486$

Brown, L. 2011. Revisiting our Roots: caring in curriculum design", Nurse Education in Practice 11:360-364

Bruenro, S,. Lamont, S and Coates, M. 2010. A review of empathy education in nursing. Nursing Inquiry $17(1) 65-74$

Burston, P and Stichler, A. 2010. Nursing work environment and nurse caring: relationship among motivational factors. Journal of Advance Nursing 66(8):1819-31

Cadman, C and Brewer, A 2001.Emotional Intelligence: a virtual pre-requisite for recruitment in nursing Journal of Nursing Management 9: 321-24

Care Quality Commission (2012) State of Care Report

Available at: http://www.cqc.org.uk/media/cqc-launch-state-care-report-2012 (Accessed 19/11/2014)

Carr, D. 2007 Character in Teaching. Journal of Education Studies 55 (4):369-89

Carter, S. 2009 Renewing pride in teaching: Using theory to advance nursing scholarship Nurse Education 9:119-26

Caruso, D,. Mayer, J and Salovey, P. 2002. Relation of an ability measure of emotional intelligence to personality. Journal of Personality Assessment 79: 306-20 Cooper, L and Olsen, M .1996. The multiple "I's" of teacher identity. In Changing research and practice: teachers' professionalism, identities and knowledge, eds M Kompf T Boak, W Bond and D, Dworet, London, Falmer Press.

Corcoran, R and Tormey R. 2013. Does emotional intelligence predict student teachers' performance?. Teaching and Teacher Education 35:34-42 
Corlett J. 2000.The perceptions of nurse teachers, student nurse and preceptors of the theory-practice gap in nurse education. Nurse Education Today 20:499-505 Corry, M and Timmins, F. 2009. The use of teaching portfolios to promote excellence and scholarship in nurse education. Nurse Education in Practice 9: 388-92 Coulehan, J and Williams, P. 2003 Conflicting professional values in medical education. Special Section: Praxis: Cambridge Quarterly of Healthcare Ethics 12:7-20 Curtis, K. 2013 21ST Century challenges faced by nursing faculty in educating for compassionate practice: embodied interpretation of phenomenological data. Nurse Education Today 33: 746-50

Darybshire, P and McKenna, L. 2013.Nursing's Crisis of care: What part does nursing education own?. Nurse Education Today 33:305-7

Day, C,. Kingston, A .,Stobart, G and Sammons P. 2006. The personal and professional selves of teachers: stable and unstable identities". British Educational Research Journal 32(4): 60116

Denzin, N .1984. On Understanding emotion, San Francisco, Josey Bass

Dickson, G. 1993. The unintended consequences of a male professional ideology for the development of nursing education. Advances in Nursing Science 15:67-83

Distler, J. 2007. Critical thinking and clinical competence: results of the implementation of student centred teaching strategies in advance practice nurse curriculum. Nurse Education in Practice 7: 51-9

Driscoll, J and The, B. 2001.The potential of reflective practice to develop individual orthopaedic nurse practitioners and their practice", Journal of Orthopaedic Nursing 5: 95- 
Drumm, J and Chase, S. 2010. Learning caring: the student's experience. International Journal of Human Caring 14(4):31-7

Duchscher J. 2000. Bending a habit: critical social theory as a framework for humanistic nursing education. Nurse Education Today 20, 453-62

Enlers, V. 2008. Is caring a lost art in nursing or is it a changing reality? Commentary on the editorial written by Juliet Corbin. International Journal of Nursing Studies 45: 802-4 Farouk, S. 2012.What can the self-conscious emotion of guilt tell us about primary school teachers' moral purpose and the relationship that they have with their pupils? Teachers and Teaching: Theory and practice 18(4):491-07

Feather, R. 2009.Emotional intelligence in relation to nursing leadership: does it matter? Journal of Nursing Management 17:376-82

Firth-Cozens, J and Cornwell, J 2009. The Point of Care Enabling compassionate care in acute hospital settings The Kings Fund.

Available from:-

https://www.kingsfund.org.uk/sites/files/kf/field/field publication file/poc-enablingcompassionate-care-hospital-settings-apr09.pdf( Accessed 24/1/2017)

Freshwater, D and Stickley T.2004. The heart of the art: emotional intelligence in nurse education. Nursing Inquiry 11(2):91-8

George J. 2000. Emotions and Leadership: the role of emotional intelligence. Human relations 53(8):1027-55

Geotz, T,. Ludtke, O., Nett, U., Keller, M and Lipnevich, A. 2013. Characteristics of teaching and students' emotions in the classroom: investigating differences across domains. Contemporary Educational Psychology 38:383-94 
Grealish, L and Smale, L. 2011. Theory before practice: implicit assumptions about clinical nursing education in Australia as revealed trough a shared critical reflection. Contemporary Nurse 39(1):51-64

Hagevik, R,. Aydeniz, M and Rowell C.2012. Using action research in middle level teacher education to evaluate and deepen reflective practice .Teaching and Teacher Education 28:675-84

Hargreaves, A .2003. The Emotions of teaching and educational change. In Extending Educational change, (ed) A Hargreaves, Netherlands, Springer Hargreaves, A .2001.Emotional geographies of teaching. Teacher College Record 103:105680

Hargreaves, A .1998. The emotional Practice of teaching. Teaching and Teacher Education $14(8): 835-54$

Hargreaves, D .2001. Creative professionalism: the role of teachers in knowledge society, London. Demos, Hegarty, S.2000. Teaching as a knowledge-based activity. Oxford review of Education 26( 3 \& 4):451-65 Henderson, A .2001.Emotional labor and nursing: an unappreciated aspect of caring work. Nursing Inquiry 8(2):130-38

Higgs, J ,. Burn, A, and Jones, M.2001.Integrating Clinical Reasoning and Evidence-based Practice AACN Clinical Issues: Advanced Practice in Acute \& Critical Care 12(4): 482-90 Horton-Deutsch, S and Sherwood, G. 2008. Reflection: an educational strategy to develop emotionally- competent nurse leaders. Journal of Nursing Management 16:946-54 
Hurley, J. 2008.The necessity, barriers and ways forward to meet user-based needs for emotionally intelligent nurses. Journal of Psychiatric and Mental Health Nursing 15:379-85 Jennings, $\mathrm{P}$ and Greenberg, M.2009. The prosocial classroom: teacher social and emotional competence in relation to student and classroom outcomes. Review of Education Research 79; 491-525

Kemp, S,. Baker, M. 2013 Continuing professional development- reflections from nursing and education. Nurse Education in practice 13(6); 541-5

Kuit, J and Rea, G.2001. Experience of reflective teaching. Active Learning in Higher Education 2(2):128-42 Landa, J and López-Zafra, E.2010. The Impact of Emotional Intelligence on Nursing. An Overview Psychology 21: 50-8 Little, M and Milliken, P.2007.Practicing what we preach: balancing teaching and clinical practice competencies. International Journal of Nursing Education Scholarship 4(1): Article $6: 1-14$

Littlejohn, P .2012.The missing link: using emotional intelligence to reduce workplace stress and workplace violence in our nursing and other health care professions. Journal of Professional Nursing, 28(6):360-68 Lofstrom, E and Nvegi, A.2013.Giving shape and form to emotion: using drawings to identify emotions in university teaching. International Journal for Academic Development 19(2):99111 Mann K. 2011.Theoretical perspectives in medical education: past experience and future possibilities. Medical Education 45:60-8 
Matsuo, M. 2012. Leadership of learning and reflective practice: an exploratory study of nursing managers. Management Learning 43:609-22

McQueen, A. 2003.Emotional intelligence in nursing work. Journal of Advanced Nursing, 47(1):101-8

Morrison, P. 1989.Nursing and caring: a personal construct theory study of some nurses' self-perception. Journal of Advanced Nursing 14(5):421 -26

Mundy, K and Denham, S. 2008. Nurse Educators- still challenged by critical thinking Teaching and Learning in Nursing 3:94-99 19

Newton, V. 2010.Teach students compassion by being an excellent role model. Nursing Practice 106(39):10

NHS England, 2013 Keogh Report. Review into the quality of care and treatment provided by 14 hospital trusts in England: overview report. Available at:

http://www.nhs.uk/NHSEngland/bruce-keogh-review/Pages/published-reports.aspx (Accessed 17/12/2014)

NHS Futures Forum (2012) Summary Report. Available at: https://www.gov.uk/government/uploads/system/uploads/attachment_data/file/216422/d h_132085.pdf (accessed 29/11/2014)

O Connor, K. 2006.You chose to care: Teachers, emotions and professional identity. Teaching and Teacher Education 24:117-26

Price, L,. Hastie L, Duffy, K., Ness, V and McCallum, J.2011. Supporting students in Clinical practice: pre-registration nursing students' views on the role of the link lecturer. Nurse Education Today 31:780-84 
Pross, E, Boykin, A, Hilton, N and Gabuat , J. 2010. A study of knowing nurses as caring. Holistic Nursing Practice 24(3):142-47

Ruth-Saad, L. 2003. Reflective Practice: A critical analysis of data-based studies and implication for nursing education .Journal of Nursing Education 42(11):488-95 Sandars, J .2009.The use of reflection in medical education. AMME Guide No 44, Medical Teachers, 31:685-95

Sanko, J., McKay, M., Rogers, S (2016).Exploring the impact of mindfulness meditation training in pre-licensure and post graduate nurses. Nurse Education Today, 45:142-147 Sargent, A. 2012. Reframing caring as discursive practice: a critical review of conceptual analyses of caring in nursing. Nursing Inquiry 19(2):134-43

Schutz, P and DeCuir, J.2002. Inquiry on Emotions in Education. Educational Psychologist $37(2): 125-34$

Schutz, P and Lanehard, S. 2002. Introduction: Emotions in Education. Educational Psychologist 3(2):67-68

Shields, C and Reid-Patton, V. 2009.A curriculum of kindness: (Re) Creating and nurturing heart and mind through teaching and learning. Brock Education 18(2):4-15 Smith, P and Allen, H. 2010. We should bear our patients in our teaching in some way: Theoretical perspectives on how nurse teachers manage their emotions to negotiate the split between education and caring practice. Nurse Education Today 30:218-23 Stoller, J,. Taylor C and Farver, C. 2013. Emotional intelligence competencies provide a development curriculum for medical training, Medical Teacher 35:243-47 Straughair, C. 2012.Exploring Compassion: implications for contemporary nursing Part 2 British Journal of Nursing 12 (4):239-44 
Sutton. R. 2004.Emotional regulation goals and strategies of teachers. Social Psychology of Education 7:379-98

Sutton, R and Wheatley, K. 2003.Teachers' emotions and teaching: A review of the literature and directions for future research. Educational Psychology Review 15(4):327-55

Tigelaar, D,. Dolmans, D,. De Grave W, I Wolfahgen, I and van der Vleuten, C. 2006.

Participants' opinions on the usefulness of teaching portfolio. Medical Education 40:371-78

Titus, P and Gremler, D. 2010. Guiding reflective practice: An auditing framework to assess teaching philosophy and style. Journal of Marketing Education 32:182-96

Titsworth, S,. Quinlan, M and Mazer, M. 2010. Emotion in teaching and learning; development and validation of the classroom emotion scale. Communication Education 59(4):431-52

Vanlaere, L and Gastmans, C. 2007. Ethics in nursing education: learning to reflect on care practice. Nursing Ethics 14:758-66

Van Veen, K and Lasky, S. 2005 .Emotions as a lens to explore teacher identity and change: different theoretical perspectives. Teaching and Teaching Education 21:895-98 Weeks, S .2012 Staff caring for my mother came across as cold and uncaring Nursing Standard 26(37):33-33

Walker, M and Mann, R. 2016. Exploring the impact of mindfulness in relation to compassion, empathy and reflection within nursing education. Nurse Education Today, 40:188-190

Wallbank, S and Proctor, S. 2013.Creating a compassionate and caring NHS: A view on the Francis Report. Journal of Health Visiting 1(3):136 
Wellar, S,. Bethune E and Heggen, K.2007.Assessment of learning in contemporary nurse education: Do we need standardised examination for nurse registration?. Nurse Education Today 27(1):68-72

Williams, G,. Dean, P and Wiliams, E. 2009. Do nurses really care? Confirming the stereotype with a case control study. British Journal of Nursing 18(3):162-65

Williams, J and Stickley, T. 2010. Empathy and nurse education .Nurse Education Today $30: 752-55$ 